\title{
BIOLOGIA FLORAL E POLINIZAÇÃO DE Aechmea beeriana (BROMELIACEAE) EM VEGETAÇÃO DE BAIXIO NA AMAZÔNIA CENTRAL.
}

\author{
Angelic Katz NARA ${ }^{1}$, Antonio Carlos WEBBER ${ }^{2}$
}

\begin{abstract}
RESUMO - O presente estudo trata a biologia floral, a polinização e o sistema reprodutivo de Aechmea beeriana Smith \& Spencer, acrescidas de algumas informações fenológicas. A espécie foi estudada nos arredores de Manaus-AM. A. beeriana ocorre principalmente como epífita a várias alturas, com preferência por locais mais sombreados. Apresenta-se adaptada a síndrome de ornitofilia, com antese diurna e inflorescências vistosas. A antese possui duração de um dia e as flores são homogâmicas. Os indivíduos são auto-incompatíveis. Três espécies de beija-flores, Phaethornis superciliosus, P. bourcieri e Thalurania furcata (Trochilinae), são considerados os principais polinizadores. A espécie apresenta padrão de floração sub-anual, com 98,4\% dos indivíduos apresentando flores ao longo do período, florescendo principalmente entre os meses de agosto e dezembro,ou seja, da metade da época de estiagem até o início da estação chuvosa. Brotos e folhas novas foram observados desenvolvendo-se ao longo do ano.
\end{abstract}

Palavras-chave: Bromeliaceae, biologia floral, sistema reprodutivo, polinização, beija-flor.

Floral Biology and Pollination of Aechmea beeriana (Bromeliaceae) in Vegetation along Stream Margins in Central Amazonia.

ABSTRACT - The present study refers to the floral biology, pollination, breeding system, and phenology of Aechmea beeriana Smith \& Spencer. The study was carried out in the region near Manaus, Amazonas, Brazil. A. beeriana occurs mainly as an epiphyte at different heights, usually in shaded places. It is adapted to ornithophily, with daytime anthesis and showy inflores cences. Anthesis lasts one day and the flowers are homogamic. The individuals are self-incompatible. Three hummingbird species, Phaethornis superciliosus, $P$. bourcieri and Thalurania furcata (Trochilinae) are considered the main pollinators. The species presented a sub-annual flowering pattern, with $94,8 \%$ of the individuals flowering mainly between the months of $\mathrm{Au}$ gust and December, i.e., from the mid dry season to the early rainy season. Shoots and new leaves developed during the whole year.

Key-words: Bromeliaceae, floral biology, breeding system, pollination, hummingbirds.

\section{Introdução}

O nome "bromélia" designa genericamente plantas monocotiledôneas da família Bromeliaceae, única integrante da ordem Bromeliales. Esta família subdivide-se em três subfamílias: Pitcairnioideae, Bromelioideae e Tillandsioideae. É composta por 50 gêneros e cerca de 3.000 taxa, incluindo-se subespécies, variedades e formas. Estima-se que aproximadamente $40 \%$ das espécies são encontradas no Brasil, o que representa quase 1.200 taxa diferentes (Leme, 1993).

As bromeliáceas da Amazônia são em geral pouco conhecidas, não

\footnotetext{
${ }^{1}$ Bolsista da Fundação Botânica Margaret Mee. Estrada de Nazaré, No 1649, Bairro Nazaré, 69700-000, Barcelos, AM, Brasil.

${ }^{2}$ Departamento de Biologia, ICB, Universidade Federal do Amazonas. Av. Gal. Rodrigo Jordão Ramos, 3000, 69077-000, Manaus, AM, Brasil.
} 
havendo estudos referentes aos aspectos da biologia floral e polinização das espécies. Segundo Smith (1955), ocorrem 64 espécies distribuídas em 14 gêneros para toda região.

As bromeliáceas em sua maioria apresentam características de ornitofilia (Smith \& Downs, 1974), estando entre as poucas famílias em que a polinização por animais vertebrados predomina sobre os insetos (Sazima et al., 1989). As bromélias ornitófilas em geral apresentam inflorescências vistosas, com brácteas vermelhas ou róseas, flores com paredes resistentes, corola tubular, néctar escondido e ausência de odor. A antese geralmente ocorre pela manhã, com grande produção de néctar e liberação de pólen (Faegri \& van der Pijl, 1979). As flores são protândricas, o que favorece a polinização cruzada (Pickersgill, 1993). De acordo com Sick (1984), o fato dos beija-flores constituírem os principais polinizadores de Bromeliaceae, sugere uma evolução paralela entre bromélias e beija-flores.

$O$ presente trabalho descreve a biologia floral, a polinização e o sistema reprodutivo de Aechmea beeriana Smith \& Spencer em vegetação de baixio, com informações fenológicas da espécie.

\section{Material e Métodos}

Este estudo foi realizado em vegetação de "baixio" (floresta de terra firme em área de baixo relevo próxima a margem de igarapés), na
Fazenda Experimental da Faculdade de Ciências Agrárias da Universidade do Amazonas, localizada no $\mathrm{Km} 38 \mathrm{da}$ BR174, estrada Manaus-Caracaraí (2。 $38^{\prime} 57,6^{\prime \prime} \mathrm{S} 60^{\circ} 3^{\prime} 11^{\prime \prime} \mathrm{W}$, alt. $96 \mathrm{~m}$ ).

Cada um dos indivíduos estudados foi marcado sendo anotadas suas características tais como, altura da roseta, comprimento e largura da bainha foliar, comprimento e largura da lâmina foliar, comprimento do pedúnculo, comprimento da ráquis, número de ráquilas, comprimento $\mathrm{e}$ largura das brácteas e comprimento dos acúleos. As flores foram descritas morfologicamente e o estigma classificado segundo Brown \& Gilmartin (1989). Foram registrados os eventos da antese, sendo coletadas informações quanto a produção $(\mu \mathrm{l})$ e concentração (\%) do néctar através do uso de um refratômetro manual. Complementarmente foram realizados testes com hidróxido de amônio, para verificar reflexão ultravioleta e SUDAN IV, para determinar a receptividade do estigma (protocolos descritos em Dafni, 1992). As observações foram feitas durante todo o período de floração, desde o início até o final da antese, em flores isoladas com "voile" (tecido sintético de malha fina), levando-se em conta, flores da base, meio e ápice das ráquilas da inflorescência. Foram realizados três tratamentos distintos: (1) extração do néctar de hora em hora em flores isoladas com "voile"; imediatamente após a coleta pelos visitantes florais; (3) em flores isoladas até próximo ao final da antese, como testemunho, para regis- 
trar o volume e a concentração total de açúcares do néctar produzido e verificar se existe variação em relação aos outros dois tratamentos.

As observações sobre a polinização foram realizadas diariamente, desde o início até o final da antese, através de observação direta, com auxílio de binóculos. Foram registradas informações relacionadas ao horário de atividade do visitante e ao seu comportamento de forrageamento na flor/ inflorescência, com posterior acompanhamento da formação de frutos. Insetos visitantes foram capturados com rede entomológica e identificados em laboratório. Não houve captura de aves visitantes. As espécies de beija-flores visitantes foram identificados no campo e através de consulta à bibliografia especializada (Hilty \& Brown, 1978; Schauense \& Phelps, 1986). Os prováveis polinizadores efetivos foram determinados através de observação direta no campo, fotografias tiradas no momento da visita às flores, registro da freqüência de visitas e comportamento dos visitantes.

Para determinação do sistema reprodutivo foram aplicados testes de polinizações controladas, entre eles: (a) autogamia com autopolinização espontânea e autopolinização artificial; (b) geitonogamia (polinização entre flores de um mesmo indivíduo); (c) xenogamia (polinização entre flores de plantas diferentes); e (d) apomixia (emasculação das flores). Todas as inflorescências manipuladas foram isoladas utilizando-se sacos de "voile".
Excetuando-se a apomixia, as flores testadas não foram emasculadas. Foram determinados dois tipos de Indivíduos controle: 1) com inflorescências totalmente isoladas com sacos de "voile"; e 2) expostas aos polinizadores (polinização aberta). Posteriormente verificou-se, em todos os indivíduos, a produção de frutos e a viabilidade das sementes, através de germinação em placas de Petri forradas com papel de filtro umedecido deixadas no ambiente onde as plantas ocorrem. Para isso, todas as infrutescências foram isoladas com sacos de filó (para evitar possível retirada dos frutos) e os frutos maduros coletados diariamente.

A fenologia foi acompanhada no campo durante o período de floração, frutificação e formação de brotos de janeiro de 1997 a março de 1998. Complementarmente foram coletados dados sobre a floração desta espécie a partir de exsicatas dos Herbários do Instituto Nacional de Pesquisas da Amazônia (INPA) e Universidade do Amazonas (HUAM) e observações não publicadas. Os padrões fenológicos foram classificados utilizando-se aqueles propostos por Newstron et al. (1994).

\section{Resultados}

\section{Caracterização dos indivíduos de Aechmea beeriana}

São plantas epífitas (Fig. 1), podendo também ser encontradas como terrestres facultativas, distribuindo-se verticalmente em todos os gradientes da floresta, ocorrendo desde a liteira, como terrestre facultativa, até o dossel, onde pode ser 


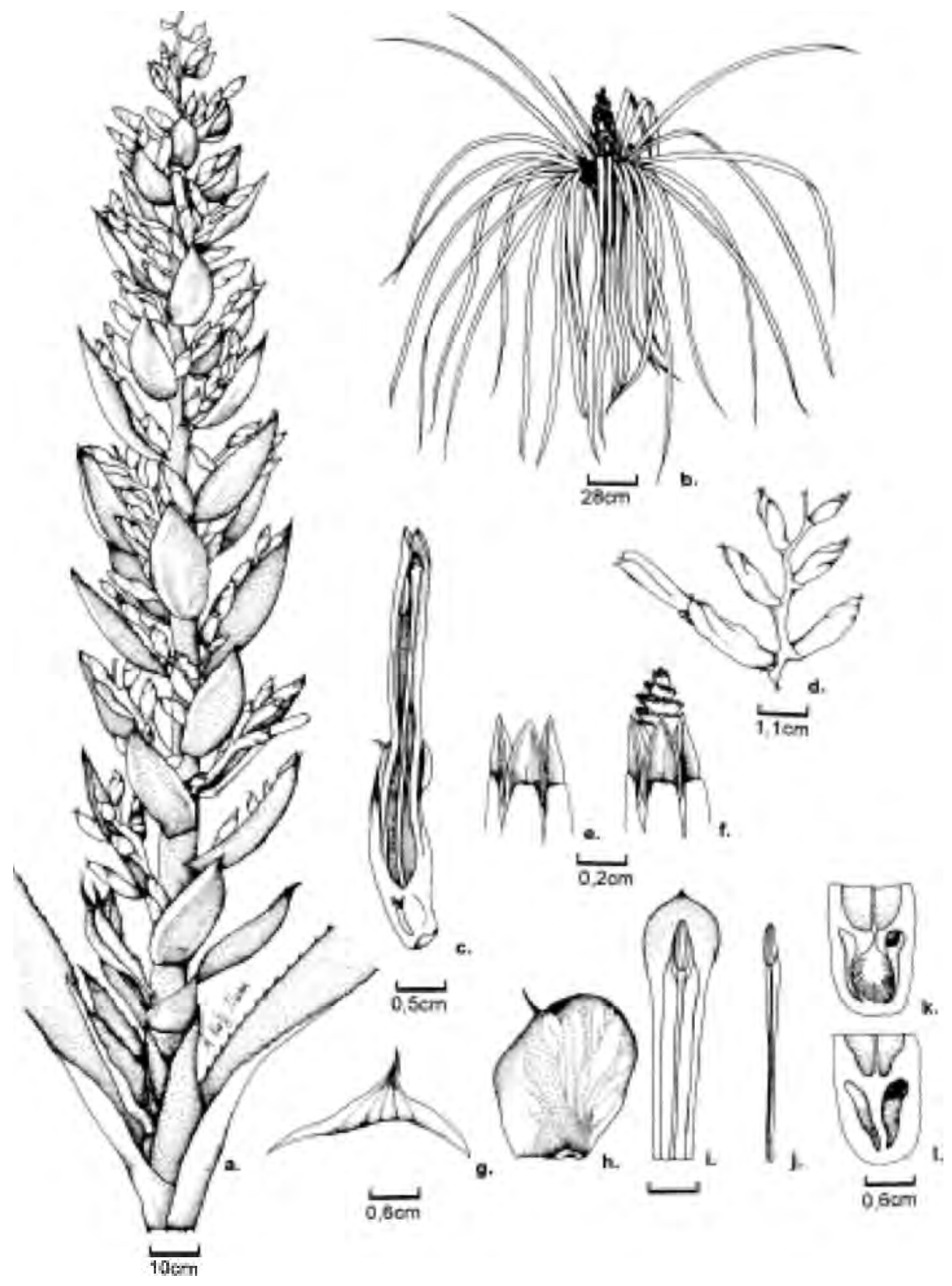

Figura 1. Aechmea beeriana: a. inflorescência; b. hábito; c. corte longitudinal da flor; d. ráquila; e. brevistilia; f. longistilia com detalhe do estigma; g. bráctea floral; h. sépala; i. pétala com um estame, mostrando lateralmente dois apêndices; $\mathbf{j}$. estame; $k$. detalhe da glândula nectarifera na flor em antese; 1. corte longitudinal do ovário. 
encontrada exposta diretamente ao sol. Apresentam rosetas densamente agrupadas, com ca. de 35 folhas. Os indivíduos possuem tamanhos variáveis (Tab. 1). As folhas são coriáceas, verdes, levemente discolores, bordo aculeado, com bainhas elípticas, bem adaptadas ao acúmulo de matéria orgânica.

\section{Morfologia das inflorescências e flores}

A inflorescência é uma panícula de espigas, cilíndrica, frouxa a densa (Fig. 1). O escapo é verde claro, pulverulento, com brácteas róseo brilhantes, paleáceas, ovaladas, alargadas na região central, serreadas a fimbriadas. A ráquis é rósea, pulverulenta com brácteas semelhantes às do escapo, as ráquilas cor de rosa, sustentando 3-9 flores cada uma. As brácteas florais são róseas, aculeadas. As flores são tubulares e sésseis, variando em média de $3,6 \mathrm{~cm}$ de comprimento nas flores do ápice a $4,4 \mathrm{~cm}$ nas flores da base das ráquilas; as sépalas são róseo-lilás tornando-se arroxeadas em direção ao ápice aculeado, contortas; as pétalas são livres, a coloração branca brilhante tornando-se azuladas no ápice. O androceu é composto de seis estames inclusos na corola, dispostos na forma de pincel logo abaixo do estigma; as anteras são versáteis, introrsas, apresentando deiscência rimosa. O ovário é ínfero, glabro, multiovular com placentação apical; o estigma é conduplicado-espiralado. O nectário é interseptal e o néctar acumulado na base da corola. Flores de diferentes indivíduos podem apresentar variações no comprimento do estilete. Os frutos são baciformes com cálice persistente e coloração azul turquesa.

A fase juvenil de uma inflorescência pode durar até três semanas. Seu desenvolvimento acontece de forma lenta até que ela atinja seu comprimento máximo, distanciando-se do tanque formado pelas bainhas foliares. Após o alongamento do escapo, os botões florais amadurecem rapidamente e as flores entram em antese. Durante seu desenvolvimento, a inflorescência é flexível, estando bem adaptada para captar o máximo da energia luminosa disponível, antes de enrijecer e perder mobilidade, com a antese das primeiras flores. Por movimentos sinuosos, a inflorescência acompanha o movimento dos raios da luz solar que adentram na floresta. Em um mesmo dia, seu pedúnculo lhe permite mover-se até $40^{\circ}$, podendo retornar à posição anterior, caso o raio de luz

Tabela 1. Dimensão mínima e máxima $(\mathrm{em} \mathrm{cm})$ observada em 18 indivíduos férteis de Aechmea beeriana.

\begin{tabular}{cccccccccccc}
\hline & AR & CBF & LBF & CLF & LLF & CP & CR & NRQ & CB & LB & CA \\
\hline Min & 10 & 2 & 2 & 115 & 3 & 12 & 10 & 15 & 5,6 & 1,4 & 0,1 \\
Max & 130 & 20 & 18 & 164 & 10 & 30 & 52 & 32 & 10 & 6 & 1 \\
Méd & $69( \pm 33)$ & $9,5( \pm 5)$ & $7,7( \pm 4)$ & $130( \pm 41)$ & $4,3( \pm 2)$ & $18( \pm 6)$ & $28( \pm 10)$ & $23( \pm 5)$ & $7,5( \pm 1)$ & $3,1( \pm 1)$ & $0,4( \pm 0,3)$ \\
\hline
\end{tabular}

AR: altura da roseta; CBF: comprimento da bainha foliar; LBF: largura da bainha foliar; CLF: comprimento da lâmina foliar; LLF: largura da lâmina foliar; CP: comprimento do pedúnculo; CR: comprimento da ráquis; NRQ: número de ráquilas; $\mathrm{CB}$ : comprimento da bráctea; LB: largura da bráctea; $\mathrm{CA}$ : comprimento dos acúleos. 
também volte a incidir no mesmo local. Após o final da floração, com o amadurecimento dos primeiros frutos, a então infrutescência, que antes estava disposta na vertical, começa a pender para o lado até ficar na horizontal. As brácteas, ráquis e ráquilas empalidecem, contrastando com os frutos de intenso azul turquesa.

\section{Biologia floral}

A antese tem duração de um dia, iniciando por volta das 06:00h. As pétalas abrem-se abruptamente permitindo o acesso ao pólen e ao néctar aos visitantes florais. $\mathrm{O}$ estigma apresenta-se receptivo, recoberto por uma camada úmida e viscosa. Anteras e estigma permanecem inclusos na corola. Não foi constatada presença de odor. As flores começam a murchar por volta das $16: 00 \mathrm{~h}$ e a borda das pétalas enrolam-se em espiral. $\mathrm{O}$ estigma deixa de ser receptivo, apresentando-se escurecido. Em testes para verificar ocorrência de reflexão aos raios ultravioleta, cálice e corola tornam-se verde-azulados, o que indica, que essas áreas refletem raios de luz ultravioleta. Após a floração desenvolve-se a infrutescência, mas a corola pode persistir por vários dias.
As sépalas, concrescidas ao ovário, desenvolvem-se junto com o fruto. constituindo parte desse.

As flores que se desenvolvem no ápice das ráquilas são visivelmente menores e menos robustas do que as flores da base, produzindo quantidades diferentes de néctar, proporcionais ao seu tamanho, o néctar ligeiramente mais concentrado nas flores da base. O somatório do volume de néctar coletado de hora em hora em flores do ápice, meio e base das ráquilas, fornece um total semelhante ao das flores cujo volume de néctar foi medido apenas no final do dia (Tab. 2). As figuras 2 e 3 demonstram respectivamente o volume de néctar $(\mu \mathrm{l})$ e a concentração média de açúcares no néctar $(\%)$ desde o início até o final da antese.

Uma inflorescềncia dura em média 31,5 dias $(\mathrm{n}=16 ; \pm 10,4 ; 14-46)$, com uma média de 3,5 flores $(n=11$; $\pm 2,2 ; 1-13)$ em antese por dia. Esse número permanece relativamente constante durante todo o período de floração, variando apenas entre inflorescências, de acordo com o tamanho da mesma. Em média são produzidos 106,5 botöes florais $(n=23$; $\pm 53,4 ; 24-232$ ), dos quais nem todos

Tabela 2. Comparaçăo do volume médio e concentraçào de néctar produzido por dia em flores do ápice $(\mathrm{n}=8)$, meio $(\mathrm{n}=8)$ e base $(\mathrm{n}=8)$ e o somatório do volume e concentraçầo do néctar coletado de hora em hora, de inflorescências de Aechmea beeriana perto de Manaus, AM. Brasil. Valores médios \pm desvio padráo (amplitude).

\begin{tabular}{ccccc}
\hline Posição & Volume $(\mu \mathrm{L})$ & Açúcar $(\%)$ & Somatỏrio $(\mu \mathrm{L})$ & Concentração $(\%)$ \\
\hline Ápice & $32 \pm 13,8(11,5-53)$ & $32 \pm 5,1(27,5-38)$ & 51,5 & 36,1 \\
Meio & $56 \pm 9,5(49-63,1)$ & $28 \pm 6,5(16-36,5)$ & 57,5 & 34,1 \\
Base & $96 \pm 6,6(87-107)$ & $35 \pm 2,5(29,5-37)$ & 89,5 & 34,1 \\
\hline
\end{tabular}


se desenvolvem, ocorrendo em média inflorescências de Aechmea beeriana. 95,4 flores por inflorescência $(\mathrm{n}=23$; Seis espécies visitaram as $\pm 48,6$; 24-232).

\section{Visitantes florais}

Os beija-flores representam o principal grupo de visitantes das

flores: Phaethornis superciliosus, Phaethornis bourcieri, Thalurania furcata, Glaucis hirsuta, Campilopterus largipenis e Florisuga melivora totalizando 223 visitas. A

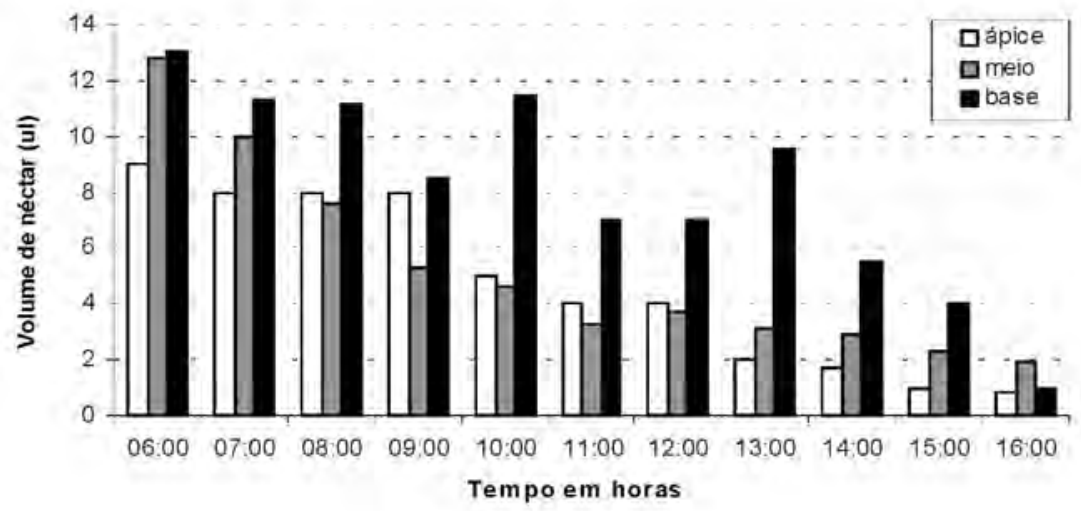

Figura 2. Produção de néctar ao longo do dia $(e m \mu l)$ em flores do ápice, meio e base de Aechmea beeriana

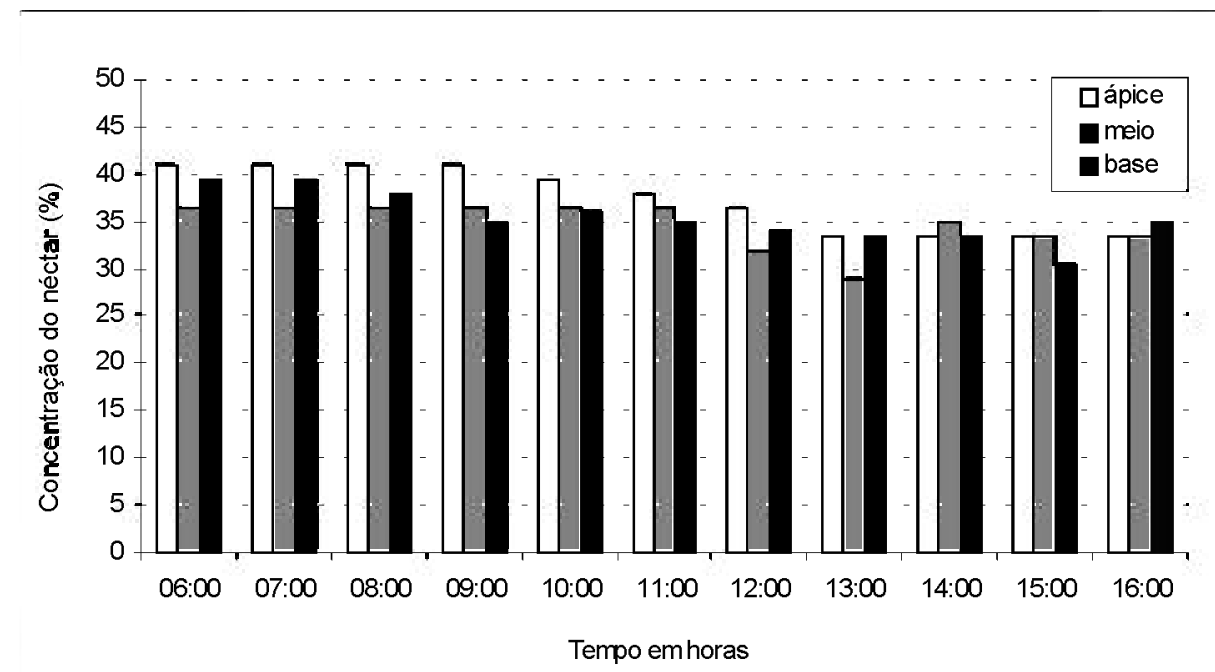

Figura 3. Concentração de açúcares no néctar ao longo do dia (\%) em flores de Aechmea beeriana. 
espécie observada com maior freqüência foi $P$. superciliosus, com $43,1 \%$ das visitas, seguido de $T$. furcata, com $25,6 \%$, e P. bourcieri, com $20 \%$, as demais espécies sendo responsáveis pelos $11,3 \%$ das visitas restantes (Fig. 4). As visitas ocorreram durante todo o dia, desde o início até o final da antese. Phaethornis superciliosus, $P$. bourcieri e Thalurania furcata visitaram todas as flores em antese na inflorescência (seis flores em média, $\mathrm{n}=46 ; \pm 3,2 ; 1-13$ ). Glaucis hirsuta, Campilopterus largipenis e Florisuga melivora visitaram em média quatro flores $(\mathrm{n}=22 ; \pm 2 ; 2-8)$. As visitas em geral são rápidas, durando em média 1,8 segundos por flor ( $\mathrm{n}=34 ; \pm 0,7 ; 1-3,7)$.

Beija-flores ermitões (subfamília Phaethorninae) em geral apresentam bicos mais compridos (em torno de $40 \mathrm{~mm}$ ) do que os não ermitões (subfamília Trochilinae) (ca. de $30 \mathrm{~mm}$ ), havendo diferença nos locais de deposição do pólen no bico das aves (Fig. 5). Em beija-flores considerados ermitões, como $P$. superciliosus e Glaucis hirsuta, o pólen é depositado na porção mediana do bico, enquanto que nas outras espécies de bico mais curto, o pólen adere próximo às narinas. Durante as visitas, os beija-flores inserem o bico no tubo floral, contatando primeiro o estigma e depois as anteras realizando assim a polinização (Fig. 6).

Apesar de diferentes espécies de beija-flores visitarem uma mesma inflorescência, não foram observados mais que dois indivíduos ao mesmo tempo. Perseguições entre indivíduos foram comuns à medida que se afastavam das plantas. Os beija-flores em geral visitavam as inflorescências vindos de diferentes direções, sendo observados numerosos leques (locais de pouso relacionados ao comportamento reprodutivo) nas proximidades. Nestes

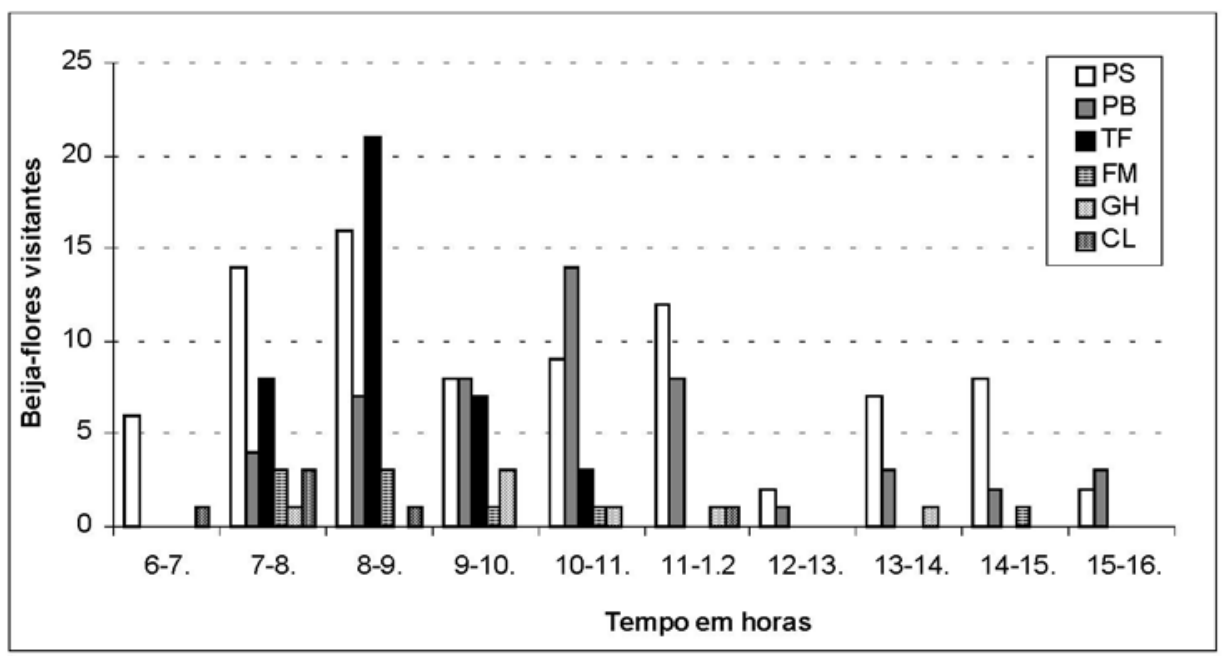

Figura 4. Freqüência de visitas realizadas por hora em Aechmea beeriana.

PS: Phaethornis superciliosus; PB: Phaethornis bourcieri; TF: Thalurania furcata;

FM: Florisuga melivora; GH: Gllaucis hirsuta; CL: Campilopterus largipenis. 
leques eles permaneciam pousados até 30 minutos sem que fossem feitas visitas às flores. Vários indivíduos de $G$. hirsuta e $P$. superciliosus foram observados em comportamento de corte, pousados nos leques ou perseguindo-se mutuamente. Também foram observados leques para $T$. furcata, que no entanto, apresentou comportamento de defesa de território. Sua área de atuação em geral envolvia uma ou duas inflorescências com leques localizados próximos, nas quais ele realizava comportamento de corte alternando visitas as inflorescências.

As abelhas (Hymenoptera) também constituem importante grupo de visitantes. Duas espécies de abelhas fo- ram observadas coletando néctar das flores. Observações realizadas quanto ao horário de visita, porte das abelhas, coloração e tamanho da probóscide, sugerem tratar-se de Eulaema sp. e Euglossa sp., ambas pertencentes â tribo Euglossini. Cerca de $90 \%$ das visitas foram realizadas por Eulaema sp. que visita as flores preferencialmente entre 08:00h e 12:00h. As abelhas pousam nas pétalas mantendo a cabeça elevada e introduzem sua probóscide na abertura do tubo floral, podendo eventualmente contatar o estigma com a mesma. Em geral todas as flores recebem visitas que duram em média, um minuto por flor $(0,6-2,33 \mathrm{~min})$, cada abelha podendo permanecer até $30 \mathrm{~min}$ em

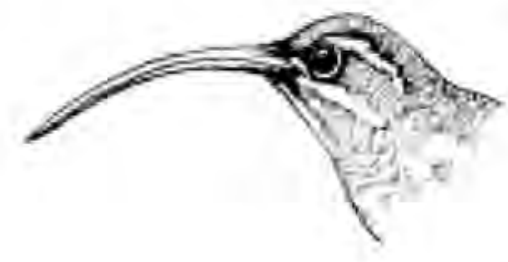

a.

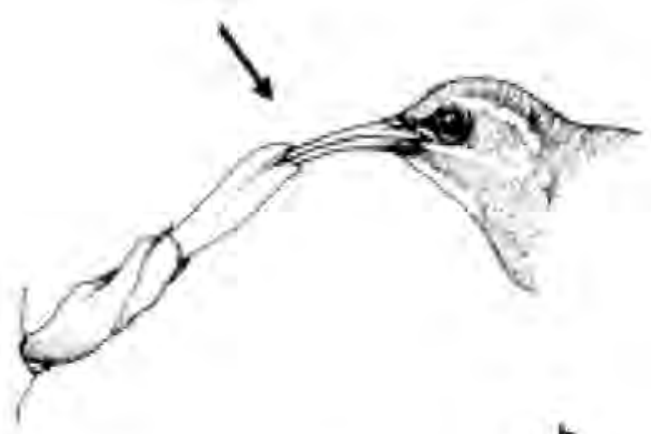

b.

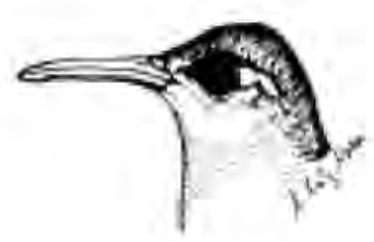

c.

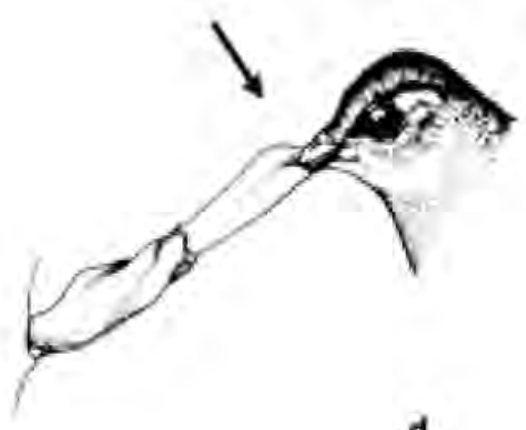

d.

Figura 5. Beija-flores. a. Phaethorninae; b. O pólen é depositado na porçâo mediana do bico; c. Trochilinae: d. O pólen é depositado próximo as narinas. 
uma mesma inflorescência. As visitas de Euglossa sp. ocorreram entre 11:00h e 12:00h. Esta espécie apresenta comportamento semelhante a Eulaema sp., embora, insira sua cabeça parcialmente no tubo floral, sem no entanto, contatar o estigma. Suas visitas duram em média quatro minutos por flor (3,5-5min), visitando de duas a três flores por inflorescência. Abelhas pilhadoras de pólen também são comuns. Vários indivíduos de Partamona sp. (Anthophoridae), Trigona williana (Apidae) e Plebeia sp. (Apidae) foram freqüentemente observados nas inflorescências coletando pólen, sem entretanto contatar o estigma. Suas visitas eram realizadas principalmente entre $08: 00 \mathrm{~h}$ e 11:00h, tornando-se raras ou ausentes durante a tarde. Além destas, vários Curculionidae (Coleoptera) eram presença constante nas flores em antese, assim como larvas de

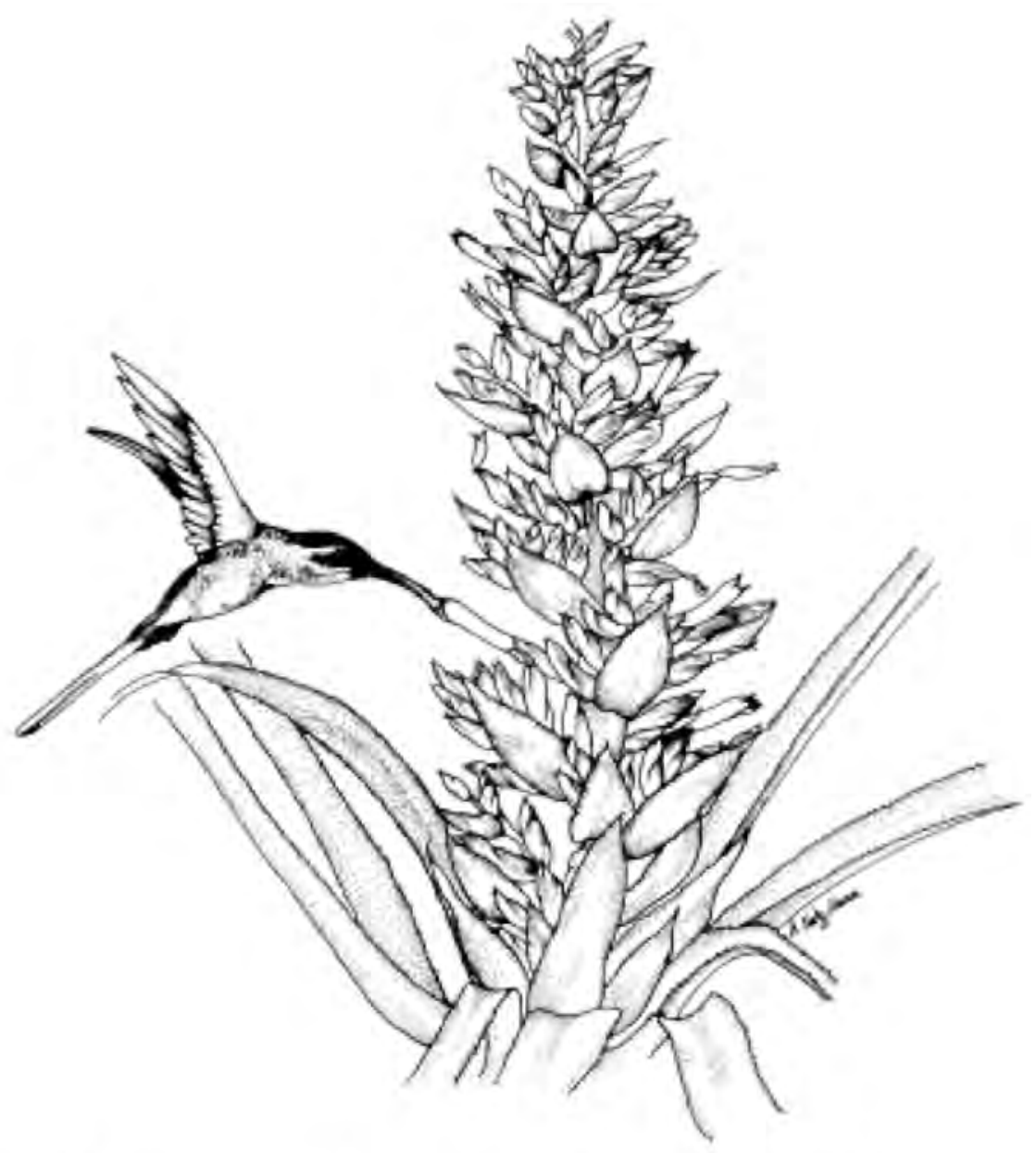

Figura 6. Phaethornis superciliosus visitando inflorescência de Aechmea beeriana. 
Diptera, provavelmente Muscidae (Droso-sphilidae), que predavam estiletes, filetes e anteras, inviabilizando a polinização. Estas, quando presentes nos botões florais, promoviam a formação de flores anormais (antese incompleta, má formação das peças florais, destruição parcial ou total das glândulas nectaríferas). Os frutos constantemente continham larvas de $\mathrm{Co}$ leoptera que se alimentavam das sementes causando sua destruição parcial ou completa. A ação conjunta das larvas de Diptera e Coleoptera, em alguns casos, ocasionou a perda completa da inflorescência/infrutescência através da destruição das flores e posteriormente dos frutos. Cerca de $30 \%$ de um total de 62 de infrutescências de $A$. beeriana foram destruídas total ou parcialmente, seja pela intensa predação observada nas flores pelas larvas de drosofilideos, seja pela ação das larvas dos coleópteros nos frutos em desenvolvimento.

\section{Sistema reprodutivo}

Os experimentos foram conduzidos em uma amostra de seis individuos. Os resultados obtidos demonstram que esta espécie é alogâmica e auto-incompatível
(Tab. 3). Além destes, foram deixados dois individuos controle com "voile" e oito expostos aos visitantes florais (Tab. 4), que sofreram intensa predação. Em média foram registrados 57,7 frutos por infrutescência ( $n=23 ; \pm 52 ; 1-130)$, o que corresponde a $57,3 \%$ do número total de flores produzidas por uma inflorescência. Amadurecem em média, por indivíduo, de 6-12,5 frutos a cada quatro dias. As sementes postas para germinar em geral levaram em média oito dias, apresentando $100 \%$ de germinação (Tab. 5). Sementes de frutos parcialmente devorados por larvas, secas e enegrecidas, também apresentaram $100 \%$ de germinação. A coloração azul-turquesa dos frutos e a coloração desbotada das brácteas da ráquis na infrutescência, são indícios de que os frutos podem ser dispersos por aves.

Após a floração, cada indivíduo emite um ou dois brotos que partem da base das rosetas foliares, formando moitas de até seis indivíduos. Geralmente estes indivíduos oriundos de reprodução vegetativa possuem crescimento rápido, florescendo no ano seguinte ao seu desenvolvimento, enquanto que indivíduos oriundos de

Tabela 3. Resultados dos testes do sisterna reprodutivo em Aechmea beeriana perto de Manaus, AM, Brasil.

\begin{tabular}{|c|c|c|c|c|c|}
\hline TRATAMENTO & $\begin{array}{l}\text { Flores } \\
\text { testadas }\end{array}$ & $\begin{array}{l}\text { Frutos } \\
\text { formados }\end{array}$ & $\begin{array}{c}\text { Sementes } \\
\text { produzidas }\end{array}$ & $\begin{array}{l}\% \text { frutos } \\
\text { formados }\end{array}$ & $\begin{array}{c}\text { Média de } \\
\text { sementes } \pm d p\end{array}$ \\
\hline Xenogamia & 41 & 29 & 874 & 70,7 & $30,1( \pm 13)$ \\
\hline Geitonogamia & 39 & 0 & 0 & 0 & 0 \\
\hline Autopolínizaçăo artificia! & 36 & 0 & 0 & 0 & 0 \\
\hline Autopolinizaçāo espontânea & 163 & 0 & 0 & 0 & 0 \\
\hline Apomixia & 26 & 0 & 0 & 0 & 0 \\
\hline Polinização aberla & 148 & 145 & 8218 & 97,9 & $56,6( \pm 26)$ \\
\hline
\end{tabular}


Tabela 4. Produção de flores e frutos por polinizaçâo e autopolinizaçâo espontânea em dez inflorescências controle de Aechmea beeriana, (a) com voile e (b) sem voile.

\begin{tabular}{|c|c|c|c|c|c|c|}
\hline \multicolumn{2}{|c|}{ Individuas } & \multirow{2}{*}{$\begin{array}{l}\text { Média de } \\
\text { flores/dia } \\
4,0\end{array}$} & \multirow{2}{*}{$\begin{array}{c}\begin{array}{c}\text { Flores } \\
\text { produzidas }\end{array} \\
82\end{array}$} & \multirow{2}{*}{$\begin{array}{c}\begin{array}{c}\text { Frutos } \\
\text { produzidos }\end{array} \\
0\end{array}$} & \multirow{2}{*}{$\begin{array}{l}\text { \% de frutos } \\
\text { produzidos }\end{array}$} & \multirow{2}{*}{$\begin{array}{c}\text { Media de } \\
\text { sementes }\end{array}$} \\
\hline (a) & 01 & & & & & \\
\hline \multirow{2}{*}{\multicolumn{2}{|c|}{$x \pm d p$}} & 3,4 & 232 & 0 & 0 & 0 \\
\hline & & $3,7 \pm 0,4$ & $157 \pm 106,1$ & 0 & 0 & 0 \\
\hline \multirow[t]{8}{*}{ (b) } & $01^{*}$ & 7,0 & 60 & 0 & 0 & 0 \\
\hline & $02^{*}$ & 2,4 & 54 & 0 & 0 & 0 \\
\hline & $03^{*}$ & 2,5 & 70 & 4 & 5,7 & 30,0 \\
\hline & $04^{\circ}$ & 2,1 & 83 & 5 & 6,0 & 28,0 \\
\hline & $05^{\circ}$ & 3,1 & 64 & 12 & 18,7 & 49,6 \\
\hline & 06 & 4,0 & 24 & 24 & 100 & 64,5 \\
\hline & 07 & 3,2 & 68 & 68 & 100 & 50,5 \\
\hline & 08 & 3,4 & 130 & 80 & 61.5 & 100.4 \\
\hline \multicolumn{2}{|c|}{$x \pm d p$} & $3,5 \pm 1,6$ & $69,1 \pm 29,9$ & $24,1 \pm 31,9$ & $34,4 \pm 45,4$ & $40,4 \pm 33,6$ \\
\hline
\end{tabular}

sementes levam mais tempo para tornarem-se férteis.

\section{Fenologia}

Acchmea beetiana floresceu durante a maior parte do ano de 1997 , excetuando-se os meses de março, abril e maio (Fig. 7). Apresenta floração do tipo subanual (Newstron et al., 1994), tendo sido observados dois picos de floração, um em janeiro e outro em outubro de 1997. A maioria dos indivíduos $(98,4 \%)$ floresceu entre agosto e dezembro, coincidindo com o período seco do ano. Dados sobre a fenologia de floração desta espécie, coletados a partir de exsicatas dos Herbários do INPA e Universidade do Amazonas e, observações realizadas por Nara \& Cruz (1996), confirmam estes resultados. Os individuos frutificaram logo após a floração, sendo possível observar-se ao mesmo tempo na população, indivíduos florescendo ou frutificando, em um processo concomitante ao desenvolvimento de brotos. Em vista disso, as touceiras em geral apresentaram indivíduos em várias fases de desenvolvimento, as folhas novas aparecendo ao longo do ano. A maioria $(94,8 \%)$ das touceiras tem um indivíduo florescendo, e somente $5,2 \%$ das touceiras tem dois. Independente disto, das 58 touceiras observadas durante o período de estudo, apenas nove $(15,5 \%)$, apresentaram-se floridas duas vezes no mesmo ano.

\section{Discussão}

Aechmea beeriana é encontrada em todos os gradientes da floresta de baixio. Apresenta grande variação

Tabela 5. Germinaçâo de sementes de Aechmea beeriana.

\begin{tabular}{lccc}
\hline & Frutos & Sementes & Germinação(\%) \\
\hline Xenogamia & 14 & 629 & 100 \\
Polinização aberta & 80 & 4577 & 100 \\
Frutos danificadas & 5 & 30 & 100 \\
\hline
\end{tabular}




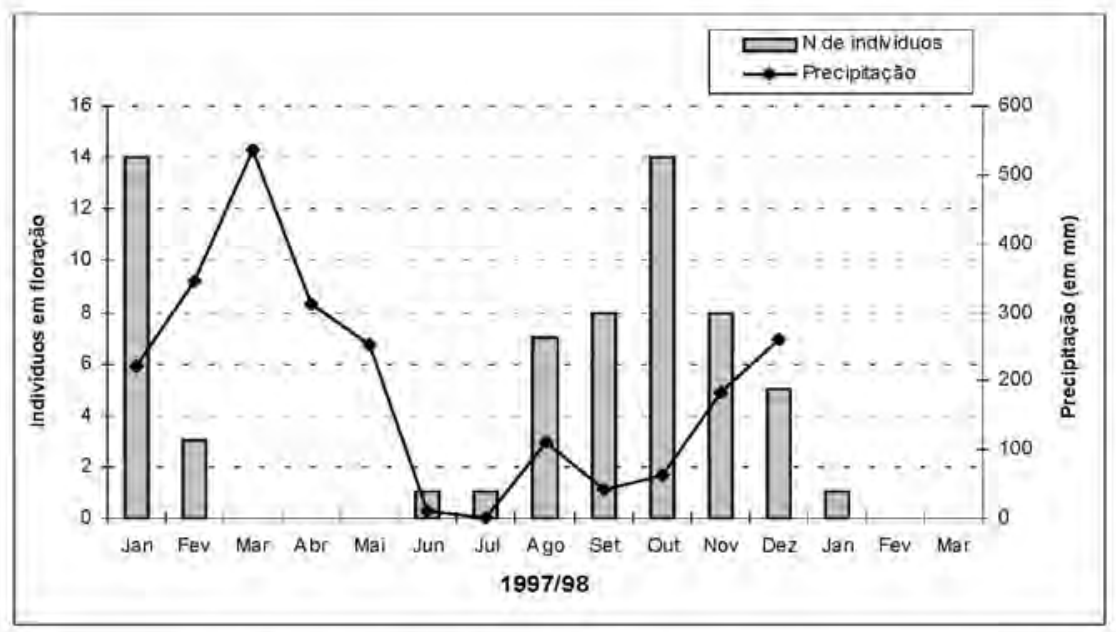

Figura 7. Freqüência de floração dos indivíduos de Aechmea beeriana versus a precipitaçào (em $\mathrm{mm})$ do ano de 1997.

fenotípica, estando aparentemente bem adaptada as variaçōes de luminosidade e umidade, observados neste tipo de vegetação. Estudos sobre a fitossociologia das bromélias têm demonstrado que estas plantas se distribuem verticalmente de forma definida e ordenada no interior da floresta, como resposta ao estímulo da luz (Veloso, 1952; Aragão, 1967). Hábito, luz, umidade e agentes dispersores, têm sido considerados os principais fatores determinantes da distribuição das espécies de bromeliáceas (Benzing, 1980).

A fase juvenil das inflorescências de $A$. beeriana dura cerca de três semanas. Smith \& Downs (1974), descrevem que em outras espécies de bromeliáceas o desenvolvimento das inflorescências pode estender-se de alguns dias a vários meses.

Aechmea beeriana é uma espécie ornitófila. Em geral, Bromeliaceae com inflorescências vistosas, com brácteas róseas ou flores de um vermelho brilhante, flexíveis, estando bem expostas a partir do interior da roseta, estão adaptadas à ornitofilia (Dahlgren et al. 1985). Além disso, o néctar é produzido em nectários interseptais, o que consiste em uma adaptação à polinização por insetos ou aves (Pickersgill, 1993).

As flores refletem os raios ultravioleta, indicando a presença de guias de néctar. Chen et al. (1984), trabalhando com receptores para ultravioleta na retina de pássaros. descreveram a visão ultravioleta para beija-flores. Kugler (1966) cita que ocorrem guias de néctar nas flores de bromeliáceas ornitófilas, embora os componentes ultravioletas dos guias de néctar sejam tênues, quando comparados aos de flores melitófilas.

As flores são homogâmicas e a antese dura um dia, tendo início pela manhã. $\mathrm{O}$ néctar está disponivel du- 
rante toda a antese, observando-se uma acentuada diminuição no volume (em $\mathrm{ml}$ ) produzido ao longo do dia. Isto se reflete na freqüência de visitas realizadas pelos beija-flores, cuja atividade tende a se concentrar durante a manhã. Sluys \& Stotz (1995) estudando padrões de visitação de beija-flores a Vriesea neglutinosa, também observaram nesta espécie uma maior concentração de visitas neste período. Em contrapartida, a diferença existente entre o volume total de néctar produzido entre flores do ápice e da base das ráquilas, não interfere na freqüência de visita dos beija-flores às inflorescências. $\mathrm{O}$ que parece ser mais importante neste caso, é o número de flores em antese por inflorescência, que influencia tanto na freqüência de visitas quanto no tempo de duração da visita às flores/inflorescência, e que está diretamente relacionado ao tamanho da inflorescência (Fischer, 1994; Suys \& Stotz, 1995).

A comparação dos dados de coleta de néctar realizadas de hora em hora, com dados referentes ao volume total de néctar produzido ao longo do dia, mostra que o volume é constante. Isto sugere que a freqüência de visitas realizadas pelos beija-flores aparentemente não altera o volume final do néctar produzido. De acordo com Pyke (1978), a decisão de mudar de touceira (inflorescência) depende de vários fatores, dentre os quais o número de flores visitadas, o número de flores na inflorescência (mais visitas às flores maiores) e a quantidade de néctar na última flor visitada. A concentração média de açúcares no néctar é de $30,7 \%$, valor semelhante aos obtidos por Fischer (1994) e Martinelli (1997), para espécies ornitófilas do Sudeste do Brasil. Entretanto, estes dados diferem dos de Stiles (1981), que considera que as flores polinizadas por pássaros produzem quantidades relativamente grandes de néctar diluído e de baixa viscosidade.

Considerando as bromélias na área estudada, observou-se que $A$. beeriana pode beneficiar-se da presença das várias espécies de beija-flores que visitam indiscriminadamente suas inflorescências. $O$ volume e a concentração do néctar versus o tamanho da inflorescência e a quantidade de flores disponíveis por dia atuam provavelmente como fatores determinantes da frequiência das visitas realizadas pelos beija-flores entre as espécies de bromélias ornitófilas alí ocorrentes. Stiles (1975) cita que o habitat pode influenciar na polinização através dos efeitos sobre o tamanho do grupo e portanto sobre o número de flores que um grupo pode apresentar de uma só vez. Fischer (1994) observou ainda que flores de corola longa (maior que $3 \mathrm{~cm}$ ) apresentam em geral néctar mais concentrado do que as flores de corola curta (menor do que $3 \mathrm{~cm}$ ). Este fato poderia estar relacionado a uma especialização entre bromeliáceas de corola longa e beija-flores de bico longo, visto que, beija-flores de bico curto aparententemente não alcançam o néctar das flores de corola longa. A deposição do pólen ocorre principalmente no bico dos beija-flores, o que é considerado comum nas Bromelioideae por Sazima 
et al. (1995), devido ao arranjo dos estames no interior do tubo da corola. Fischer (1994) descreve resultados semelhantes para 17 espécies de bromélias ornitófilas (nove pertencentes a Bromelioideae e oito a Tillandsioideae).

Duas espécies de beija-flores foram consideradas as principais visitantes: Phaethornis superciliosus e Thalurania furcata. O ermitão, Phaethornis superciliosus, foi a espécie mais freqüentemente observada. Em seguida vieram espécies consideradas territorialistas, como Thalurania furcata e Phaethornis bourcieri, seguido das demais espécies. Os Phaethorninae parecem constituir o principal grupo de beija-flores polinizadores de Bromeliaceae. Phaethornis superciliosus também tem sido descrito como principal visitante de Aechmea magdalenae (Murawski \& Hamrick, 1990). Araújo et al. (1994) e Fischer (1994) relatam que ca. de $70 \%$ das espécies de bromélias que ocorrem na região estuarina do Rio Verde (Juréia, SP, Brasil), partilham o uso de Ranphodon naevius (Phaethorninae), através de florações seqüenciais e da deposição de pólen em diferentes partes do corpo desta ave. Além disso, de acordo com Sazima et al. (1995), este beija-flor parece ser um polinizador bastante importante de flores de bromélias em vários locais da Mata Atlântica no Sudeste do Brasil. Embora não tenha sido observado, Stiles (1975) cita que a polinização feita por beijaflores ermitões tendem a produzir mais polinização cruzada, enquanto beijaflores territorialistas aumentam a autopolinização.
As abelhas foram consideradas pilhadoras de néctar, uma vez que não contatavam o estigma, competindo com os beija-flores por este recurso. Do mesmo modo, vários indivíduos de Partamona sp. e Plebeia sp. (Hymenoptera) foram observados pilhando pólen das flores, semelhante ao que ocorre com Apis melifera em Dyckia floribunda (Bernadelo et al., 1991).

Aechmea beeriana é uma espécie alógama, auto-incompatível. Para Endress (1994), a auto-incompatibilidade é a principal estratégia que leva a polinização cruzada.

Muito pouco tem sido publicado a respeito do sistema reprodutivo de Bromeliaceae (Gentry \& Dodson, 1987; Martinelli, 1997). As informações são esparsas e o impacto sobre a estrutura genética, o isolamento das populações e a especiação permanecem em grande parte desconhecidos (Benzing, 1994). Apenas umas poucas populações de espécies predominantemente epífitas, como Tillandsia ionantha e $T$. recurvata (Soltis et al.,1987), e terrestre, como Aechmea magdalenae (Murawski \& Hanrick, 1990), foram examinadas de forma mais completa para determinar estruturas genéticas.

Aechmea beeriana aparente-mente encontra-se adaptada à dispersão ornitocórica. Infrutescências coloridas e conspícuas em posição inclinada ou horizontal, em geral favorecem o uso das mesmas como poleiros pelos passeriformes (Leme, 1993; Fischer \& Araújo, 1995).

$A$ floração é subanual, estando aparentemente relacionada ao início da 
estação seca (junho e julho), o que sugere a importância de um stress hídrico como fator desencadeador deste processo. Nos meses de abril e maio não ocorre floração das bromeliáceas de baixio nesta região. Este fato pode estar relacionado à umidade excessiva observada neste período, em que se chegou a registrar um índice de precipitação superior a $500 \mathrm{~mm}$ num mês. No entanto, é importante ressaltar que o ano de 1997 foi um ano atípico do ponto de vista ecoclimático, devido ao fenômeno " $E 1$ Nino". Após a floração observou-se que a frutificação ocorre de forma gradual e contínua, a espécie aparentemente encontrando-se bem adaptada à dispersão ornitocórica, uma vez que os frutos em geral são dispersos assim que amadurecem.

O período de floração parece estar relacionado à reprodução de algumas espécies de beija-flores, tornando-se evidente a presença de "leques", principalmente para Phaethornis superciliosus, Glaucis hirsuta e Thalurania furcata. Pôde ser observado comportamento de corte e acasalamento, em Thalurania furcata estando associado à defesa de território.

Outras espécies de bromeliáceas ornitófilas ocorrem na mesma área ocupada por Aechmea beeriana (Aechmea bromeliifolia, A. contracta, Gusmania lingulata e Gusmania sp.) e, também floresceram durante o segundo semestre de 1997 (informação não publicada), competindo pelos mesmos agentes polinizadores. Diferenças na coloração, tamanho e número de flores disponíveis podem diminuir esta competição. Segundo Fischer (1994), quando há casos de competição interespecíficas por polinizadores, a espécie mais favorecida será a que apresentar maior quantidade de flores por inflorescência e maior número de flores em antese por dia, associado a um nível mais elevado de concentração de açúcares no néctar.

\section{Conclusões}

A partir dos resultados obtidos pode-se concluir que: Aechmea beeriana é uma espécie ornitófila; os beija-flores Phaethornis superciliosus, Thalurania furcata e Phaethornis bourcieri constituem os seus principais polinizadores; Aechmea beeriana apresenta reprodução sexuada, sendo uma espécie alogâmica e autoincompatível, e também reprodução assexuada, dada pela formação de brotos; Aechmea beeriana apresenta floração subanual, com a maioria dos indivíduos florescendo de julho a dezembro, coincidindo com a estação seca do ano.

\section{Agradecimentos}

Agradecemos ao INPA e Universidade do Amazonas pelo apoio logístico e financeiro; A.F. de Figueiredo, J. da Cruz, S.S. Silva, Funcionários da Fazenda Experimental da Universidade do Amazonas pelo apoio; S.H. Borges pelo auxílio na identificação dos beija-flores; F.J.A. Peralta pela identificação dos insetos; R. Gribe1, M.J.G. Hopkins, M. Sazima, M.L. Absy, pelos comentários 
e sugestões apresentadas.

\section{Bibliografia citada}

Aragão, M.B. 1967. Condições de habitat e distribuiçāo geográfica de algumas Bromeliaceae. Sellowia, 19:79-135.

Araújo, A.C.; Fischer, E.A.; Sazima, M. 1994. Floração seqüencial e polinização de três espécies de Vriesea (Bromeliaceae) na região da Juréia, sudeste do Brasil. Rev. Brasil. Bot., 17:113-118.

Bush, S.P.; Beach, J.H. 1986. Breeding systems of epiphytes in a tropical montane wet forest. Selbiana, 16(2):155-158.

Bernadello, L.M.; Galetto, L.; Juliami, H.R. 1991. Floral nectar, nectary structure and pollinators in some Argentinian Bromeliaceae. Annals of Botany, 67:401-411.

Brown, G.K.; Gilmartin, A.J. 1989. Stigma types in Bromeliaceae - A systematic survey. Systematic Botany, 14(1):110-132.

Chen, D.M.; Collins, J.S.; Goldsmith, T.H. 1984. The ultraviolet receptor of bird retinas. Science, 225:337-40.

Dahlgren, R.M.T.; Clifford, H.T.; Yeo, P.F. 1985. The families of the Monocotyledons. Structure, evolution and taxonomy. Springer-Verlag Berlin. 520p.

Dafni, A. 1992. Pollination ecology. A practical approach. Oxford University Press, New York. 250p.

Endress, P.K. 1994. Diversity and evolutionary biology of tropical flowers. Cambrige University Press, New York. 510p.

Faegri, K.; Pijl, L. van der. 1979. The principles of pollination ecology. Pergamon Press, New York. 244p.

Fischer, E.A. 1994. Polinização, fenologia e distribuição espacial de Bromeliaceae numa comunidade de Mata Atlântica, litoral sul de São Paulo. Dissertação de Mestrado, Universidade Estadual de Campinas. Campinas, São Paulo. 80p.

Fischer, E.A.; Araújo, A.C. 1995. Spatial organization of a bromeliad community in the Atlantic rainforest, south-eastern Brazil. Journal of Tropical Ecology, 11:559-567.

Fontoura, T.; Costa, A.F.; Wendt, T. 1991. Pre- liminary checklist of the Bromeliaceae of Rio de Janeiro State, Brazil. Selbiana, 12:5-45.

Gentry, A.H.; Dodson, C.H. 1987. Diversity and biogeography of neotropical vascular epiphytes. Ann. Mo. Bot. Gard., 74:205-233.

Hilty, B.S.; Brown, W.L. 1978. A guide to the birds of Colombia. Princeton University Press, Princeton. 487p.

Kugler, H. 1966. UV-Male auf Blüten. Ber. Deutsch. Bot. Ges., 79:57-70.

Leme, E.M.C. 1993. Bromélias na natureza. Marigo Comunicações Visuais Ltda., Rio de Janeiro. 183p.

Martinelli, G. 1997. Biologia reprodutiva de Bromeliaceae na Reserva Ecológica de Macaé de Cima. In: Lima, H.C.; Guedes Bruni, R.R. (Eds). Serra de Macaé de Cima: Diversidade florística $e$ conservação em Mata Atlântica. Jardim Botânico do Rio de Janeiro, Rio de Janeiro. 346p.

Murawski, D.A.; Hanrick, J.L. 1990. Local genetic and clonal structure in the tropical ter restrial bromeliad, Aechmea magdalenae. Amer. J. Bot., 77(9):1201-1208.

Newstron, L.E.; Frankie, G.W.; Baker, H.G. 1994. A new classification for plant phenology based on flowering patterns in lowland tropical forest trees at La Selva, Costa Rica. Biotropica, 26(2):141-159.

Pickersgill, B. 1993. Bromeliaceae. The Pineapple family. In: Heywood, V.H. (Ed.) Flowering plants of the world. Andromeda Oxford, London, p.294-296.

Pyke, G.H. 1978. Optimal foraging in hummingbirds: testing the marginal value theorem. Amer. Zool., 18:739-752

Sazima, I.; Vogel, S.; Sazima, M. 1989. Bat pollination of Encholirium glaziovii, a terrestrial bromeliad. P1. Syst. Evol., 168:167-179.

Sazima, M.; Buzato, S.; Sazima, I. 1995. Polinização de Vriesea por morcegos no Sudeste Brasileiro. Bromelia, 2(4):29-35.

Sick, E. 1984. Ornitologia brasileira, uma introdução. Ed. Universidade de Brasília, Brasília,. Vol.1. 481p. 
Stiles, F.G. 1975. Ecology, flowering phenology, and hummingbird pollination of some Costa Rican Heliconia species. Ecology, 56:285-301.

Stiles, F.G. 1981. Geographical aspects of birdflower coevolution, with particular reference to Central America. Ann. Missouri Bot. Gard., 68:323-51.

Shauensee, R.M.; Phelps, W.H. 1986. A guide to the birds of Venezuela. Princeton University Press, Princeton. 424p.

Sluys, M.V; Stotz, D.F. 1995. Padrões de visitação a Vriesea neglutinosa por beijaflores no Espírito Santo, sudeste do Brasil. Bromelia, 2(3):27-35.

Smith, L.B. 1955. The Bromeliaceae of Brasil. Smithsoniam Misceleneaus Collection, 126(1):144-157.

Smith, L.B.; Downs, R.J. 1974. Pitcairnioideae (Bromeliaceae). Flora Neotropica. Monogr., Hafner Press, New York, 14(1):1-58.

Soltis, D.E.; Gilmartin, A.J.; Rieseberg, L.; Gardner, S. 1987. Genetic variation in the epiphytes Tillandsia ionantha and Tillandsia recurvata (Bromeliaceae). American Journal of Botany, 74:531-537.

Veloso, H.P. 1952. O problema ecológico: vegetação-Bromeliaceae-anofelinos. I. A presença relativa das formas aquáticas do Anopheles (Kerterszia) spp como índice de positividade das espécies de bromeliáceas. Sellowia, 4:187-240.

Aceito para publicação em 06/08/2002. 